\title{
A Modern Guide to Keynesian Macroeconomics and Economic Policies
}

\author{
Resenha de \\ Fernando Ferrari Filho*
}

O processo de globalização financeira, em que os mercados financeiros são integrados de tal forma a criar um "único" mercado mundial de dinheiro e crédito, diante de um quadro em que inexistem regras monetário-financeiras e cambiais estabilizantes, e os instrumentos tradicionais de política macroeconômica se tornam crescentemente insuficientes para conter os colapsos financeiros (e cambiais) em nível mundial, tem resultado em frequentes crises de demanda efetiva, determinado fundamentalmente por "forças financeiras".

Defato, a crise financeira que emergiu em 2007-2008, cujos desdobramentos ainda se fazem sentir nos dias de hoje, mais especificamente na crise fiscalfinanceira dos países da zona do euro, é, sobretudo, a crise da globalização financeira, entendida como uma tendência à criação de um mercado financeiro global e de intensificação no fluxo de capitais entre países. Esse processo tem como origens a ruptura do sistema de Bretton Woods, a desregulamentação dos sistemas financeiros nacionais e a liberalização dos fluxos de capitais.

John Maynard Keynes, em sua The General Theory of Employment, Interest and Money, doravante GT, de 1936, chamava a atenção para o fato de que, em economias monetárias da produção, a organização dos mercados financeiros enfrenta um trade-off entre liquidez e investimento: por um lado, eles estimulam o desenvolvimento da atividade produtiva ao tornar os ativos mais líquidos, liberando, portanto, o investidor da irreversibilidade do investimento; por outro lado, eles aumentam as possibilidades de ganhos especulativos. Assim, ao estabelecer uma conexão entre os mercados financeiro e real da economia, Keynes na GT (New York: HBJ Book, 1964, p. 159) escreve que "[...] a posição é séria quando o empreendimento torna-se uma bolha sobre o redemoinho da especulação. Quando o desenvolvimento das atividades de um país tornase o subproduto das atividades de um cassino, o trabalho provavelmente será malfeito".

Indo ao encontro de Keynes, nos dias de hoje, a ação dos global players, em um mercado mais liberalizado e integrado, faz com que os mercados financeiros convertam-se em uma espécie de grande cassino global. Especulação, em uma economia global, tem caráter disruptivo não somente em mercados domésticos, mas sobre países como um todo, criando uma espécie de cassino financeiro ampliado. A crise financeira internacional de 2007-2008 e seus desdobramentos suscitam três reflexões. Em primeiro lugar, ela põe em xeque os benefícios

Professor titular da Universidade Federal do Rio Grande do Sul (UFRGS) e pesquisador do CNPq. E-mail: ferrari@ufrgs.br 
concretos da globalização financeira, com mercados financeiros desregulados, inclusive nos países desenvolvidos. Em segundo lugar, ela nos remete, a partir das medidas contracíclicas de natureza fiscal e monetária implementadas pelas autoridades econômicas na maioria dos países para se evitar a repetição de uma grande depressão, tanto a repensar o próprio papel do Estado na economia quanto a necessidade de se regulamentar os sistemas financeiros nacionais e reestruturar o sistema monetário internacional. Por fim, ela, por um lado, questiona a lógica e as implicações econômicas dos modelos teóricos que alicerçaram o processo de globalização financeira ao longo das últimas duas décadas, entre os quais o Novo Consenso Macroeconômico (NCM), e, por outro lado, representa "[...] a revival of Keynesian economics, both in terms of academic reserach and in terms of macroeconomic policies" (HEIN; STOCKHAMMER, 2011, p. xii).

Pois bem, o livro A Modern Guide to Keynesian Macroeconomics and Economic Policies, editado por Eckhard Hein e Engelbert Stockhammer, vai na direção da terceira reflexão. Nesse particular, os colaboradores do referido livro não somente mostram o que Keynes e os pós-keynesianos tinham e têm a dizer sobre a dinâmica de economias monetárias, financeirização da riqueza e crises financeiras, como, também, sinalizam quais são as políticas macroeconômicas e a institucionalidade possíveis para se alcançar a prosperidade econômica. Para tanto, o livro divide-se em 13 capítulos.

O capítulo 1, escrito por Marc Lavoie, (i) apresenta a evolução do pensamento pós-keynesiano e seus princípios metodológicos, (ii) mostra que a teoria pós-keynesiana tem uma relação de afinidade e complementaridade com outras escolas heterodoxas de pensamento econômico e (iii) analisa tanto os principais pressupostos dos programas de pesquisa heterodoxo e ortodoxo, quanto as controvérsias que rocked a economia pós-keynesiana. Ao analisar as controvérsias entre os pós-keynesianos, Marc Lavoie conclui que há future avenues a serem exploradas pela agenda de pesquisa pós-keynesiana que vão além do princípio da demanda efetiva e da distribuição, entre as quais, questões ambientais e ecológicas.

No capítulo 2, também de autoria de Marc Lavoie, é analisado o papel da moeda, do crédito e dos bancos na economia pós-keynesiana. Nesse sentido, três seções chamam a atenção: a seção 2 descreve a funcionalidade dos sistemas monetário-financeiros nas concepções pós-keynesiana e ortodoxa; a seção 4 mostra a controvérsia pós-keynesiana sobre a endogenia (ou não) da oferta de moeda - horizontalismo vis-à-vis estruturalismo; e as seções 5 e 6, que são "complementares", apresentam os novos mecanismos operacionais de condução da política monetária, entre os quais o regime de metas para a inflação, e suas implicações nos desdobramentos da crise financeira do subprime.

Amitava Dutt, no capítulo 3, discute crescimento econômico e distribuição de renda na perspectiva pós-keynesiana. Nesse sentido, ao desenvolver um modelo pós-keynesiano básico sobre crescimento e distribuição, o autor deixa clara a influência de Marx, Kalecki e Kaldor no referido Modelo. Esse capítulo 
se conclui apresentando as implicações para o modelo pós-keynesiano básico quando são inseridas algumas variáveis nele, entre as quais, taxa de juros constante em conformidade com o princípio horizontalista da oferta de moeda, mudanças tecnológicas e taxa de inflação.

No capítulo 4, Philip Arestis apresenta o NCM para uma economia aberta. A ideia é mostrar que esse NCM, à luz da teoria keynesiana, possui sérios problemas teóricos e operacionais. Entre as principais críticas, Philip Arestis argumenta que os fundamentos teóricos do NCM para uma economia aberta têm dois problemas, "[b]oth emante from the absence of money and bank in the NCM model, and from the way the equilibrium real ratye of interest is utilised in the same model" (Ibid., p.105-6).

Eckhard Hein e Engelbert Stockhammer apresentam suas contribuições no capítulo 5, que analise o modelo pós-keynesiano para a inflação, a distribuição e o emprego. Nesse modelo, a inflação deriva do conflito distributivo. A renda é apropriada por três classes sociais: rentistas, empresários e trabalhadores. E o crescimento é dinamizado pela lógica da função investimento kaleckiana. Após algumas suposições e considerações, os autores concluem que estabilização inflacionária e "pleno emprego" são assegurados quando: "The central bank should stabilise distribution between rentiers, firms and labourers, and set low real interest rates [...] and should contribute to stabilising the financial sector [...]; wagebargaining parties should target inflation; and fiscal policies should be applied for short-and-medium-run real stabilisation purposes" (Ibid., p.132).

No capítulo 6, Eckhard Hein discute a macroeconomia do desemprego. A ideia é mostrar que, em economias monetárias, o desemprego é "mostly involuntary and that it is caused by a shortage of aggregate demand" (Ibid., p.137). Para tanto, o capítulo mostra, inicialmente, como o nível de emprego é determinado no modelo de Keynes. Na seção seguinte é apresentado um modelo pós-keynesiano de determinação do nível de emprego em que as firmas são price-makers e há uma Curva de Phillips de curto prazo. As conclusões são de que a intervenção do governo é requerida para assegurar o "pleno emprego". Nas palavras do autor, "policy recommendations are traditional Keynesian active fiscal and monetary policy accompanied by incomes policy" (Ibid., p.158). Ou seja, as mesmas proposições de Keynes no capítulo 24 da GT.

O capítulo 7, de David R.Howell, analisa a relação entre instituições, demanda agregada e emprego. O argumento central é que as políticas de desregulamentação do mercado de trabalho e, por conseguinte, reformas trabalhistas não conseguiram assegurar condições de "pleno emprego" e de salários decentes. Em contrapartida, "[...] the Keynesian aggregate demand model embedded in a comparative political economy perspective has the potential to offer a far more convincing explanation [...] of cross-country patterns of employment performance" (Ibid., p.185).

Philip Arestis retorna no capítulo 8 discutindo a economia europeia e as políticas da união monetária em uma perspectiva keynesiana. Oobjetivoémostrar que a estrutura teórica da União Monetária Europeia (UME) está alicerçada no NCM. Segundo o autor, as restrições fiscal e monetária impostas pelo Pacto de 
Crescimento e Estabilidade acabam não assegurando as condições de "pleno emprego" e estabilidade inflacionária na UME, principalmente pelo fato de que não é admissível que "one size fits all". Alternativamente, à luz da teoria keynesiana, Philip Arestis apresenta uma proposição de políticas econômicas e arranjos institucionais para que sejam assegurados, na UME, "pleno emprego" e baixa inflação.

O capítulo 9, escrito por Robert A.Blecker, apresenta um modelo póskeynesiano de distribuição de renda e crescimento econômico para uma economia aberta. O objetivo é mostrar como as variações cambiais (por exemplo, desvalorização da taxa de câmbio) acabam afetando a distribuição de renda e, por conseguinte, na tradição dos modelos kaleckianos, o crescimento econômico.

Globalização, performance macroeconômica e distribuição é a discussão do capítulo 10, apresentada por Özlem Onaran. O objetivo do autor é mostrar como a globalização do capital, tanto sob a forma de investimento direto estrangeiro quanto sob a forma de comércio internacional, acaba afetando a dinâmica macroeconômica e o nível de distribuição renda dos países. Para tanto, na seção 3 Özlem Onaran, entre alguns dos inúmeros modelos póskeynesianos, explora o argumento do modelo de crescimento econômico com restrição de balanço de pagamentos de Thirlwall e McCombie. A principal conclusão do autor é de que a liberalização da conta comercial do balanço de pagamentos e a livre mobilidade de capitais acabaram criando desigualdades e desequilíbrios globais. Nesse sentido, a correção dessa situação passa, entre outras medidas, pela "[...] regulation of financial markets and controlo $f$ capital flows" (Ibid., p. 261).

O capítulo 11, escrito por Hansjörg Herr, discute a arquitetura financeira e monetária internacional. Por um lado, o capítulo mostra que, desde a ruptura do sistema de Bretton Woods, a economia mundial tem sido mais exposta a crises cambiais e financeiras. Por outro lado, o autor apresenta uma proposição de reforma do sistema financeiro internacional baseado tanto na International Clearing Union de Keynes, quanto na International Money Claering Union de Davidson.

No capítulo 12, Eckhard Hein relaciona financeirização, distribuição de renda e crescimento econômico. Inicialmente, o autor apresenta os canais de transmissão da financeirização sobre o investimento das firmas, o consumo das famílias, a distribuição da renda e o regime macroeconômico. Em seguida, Eckhard Hein elabora um modelo de stock-flow pós-keynesiano/ kaleckiano de distribuição de renda e crescimento para analisar os efeitos que a financeirização exerce sobre ele. Nesse particular, a financeirização torna o modelo sistemicamente instável.

Por fim, o capítulo 13, escrito por Gary Dymski, analisa a crise financeira à luz da teoria (pós)keynesiana. Nesse sentido, as ideais de Keynes e de Minsky sobre crise financeira são revisadas. Centrando a análise em Minsky, o autor corrobora o ponto de vista desse sobre a natureza da instabilidade financeira de que está relacionada ao fato de que a "estabilidade é desestabilizadora". 
Gary Dymski, na última seção, mostra as origens e os desdobramentos das crises financeiras durante a era neoliberal, particularmente a do subprime. Enfim, o livro editado por Eckhard Hein e Engelbert Stockhammer é uma contribuição interessante e importante para aqueles que querem compreender o modus operandi de economias monetárias em um contexto de globalização financeira e refletir sobre os principais desafios econômicos com que se defronta a economia global. Para finalizar, não é demais ressaltar que a importância do livro é corroborada pelo fato de que, desde a crise do subprime, a economia mundial tem convivido com situações tanto de "Momento Minsky", em que a crescente fragilização financeira acabou resultando na atual crise financeira internacional, quanto de "Momento Keynes", em que os governos dos países desenvolvidos e emergentes passaram a adotar políticas fiscal e monetária contracíclicas para mitigar os impactos da referida crise sobre o lado real da economia.

\section{Referência}

ECKHARD, Hein; STOCKHAMMER, Engelbert (Ed.). A modern guide to Keynesian macroeconomics and economic policies. Cheltenham: Edward Elgar, 2011. 365 p. 